\title{
Relational equality and the expressive dimension of state action
}

Kristin Voigt, Institute for Health and Social Policy \& Department of Philosophy, McGill University

email: kristin.voigt@mcgill.ca

Final version forthcoming in Social Theory \& Practice.

\begin{abstract}
Expressive theories of state action seek to identify and assess the 'meaning' implicit in state action, such as legislation and public policies. In expressive theories developed by relational egalitarians, state action must 'express' equal concern and respect for citizens. However, it is unclear how precisely we can determine and assess the meaning of what states do. This paper considers how an expressive theory could be developed, given the commitments of a relational account of equality, and how such a theory would relate to relational egalitarianism more broadly. I suggest that expressive considerations should be tied more closely than they are in the current literature to agents' attitudes and to their intentions. I discuss a range of real-world policies that are problematic for what they can be taken to express.
\end{abstract}

\section{Introduction}

The growing literature on relational egalitarianism has called attention to the importance of relationships between individuals for conceptions of equality. However, many aspects of the relational account have yet to be developed. In this paper, I focus on the possible implications of relational equality for the 'expressive dimension' of state action, which seeks to assess the 'meaning' implicit in state action, such as legislation and public policies. ${ }^{1}$ Proponents of such an expressive theory include Elizabeth Anderson, who is also one of the central advocates of a relational view of equality. While Anderson has not explicitly linked her endorsement of an expressive theory of state action to her ideas about relational equality, there are clear continuities between the requirements of an expressive theory as she develops it and relational equality more broadly, and the link has been made explicit by other contributors to this literature.

This paper considers how an expressive theory should be developed, given the commitments of a relational account of equality, how such a theory would relate to relational egalitarianism more broadly, and what it might tell us about the requirements state action must meet. I argue that expressive concerns should be tied more closely to speakers' attitudes and intentions than they are in the current literature. Using real-world cases, I then suggest a number of ways in which individual policies can become problematic from this perspective.

1 I first became interested in the expressive dimension of state action as part of co-authored work on relational equality and health (Voigt and Wester 2015). I draw on this paper at various points in the discussion here. 
Expressive considerations highlight an important dimension of what states do, and allow for a more nuanced assessment of policies and other kinds of state action. Analysis of the expressive dimension of actions is crucial not least because many actions - and responses to them - can be fully understood only once we allow that such actions have, or can be taken to have, a particular meaning. Consider, for example, the recent North Carolina bathroom laws, which I will briefly discuss below. Concern and outrage about this legislation was based not only on its actual content and likely effects but also on what it was taken to express. While the focus of this paper is on state action, expressive considerations can also apply in the context of individual action. Think, for example, of the burning of national flags in protest, refusing to sing, or stand for, a national anthem, or demonstrations in which citizens seek to express solidarity with the victims of injustice. Understanding such actions arguably requires an appreciation of their expressive dimension.

The paper begins by outlining the central arguments and positions of the relational account and its understanding of equality. The literature has defined relational equality in different ways. I identify the main interpretations of what relational equality might require (section 2). I then outline the basic idea of an 'expressive theory' of state action and its links to relational equality (section 3). I argue for some revisions to how the expressive dimension of state action is to be understood (section 4), before suggesting what kinds of state actions and policies such a theory might single out as problematic, and on what grounds (section 5).

\section{Relational egalitarianism(s)}

At the core of relational egalitarianism is the idea that what matters from the perspective of equality is how individuals relate to one another, particularly in their capacity as citizens. Proponents of relational egalitarianism have described their accounts as aiming for 'equality of status' (Miller 1997), 'social equality' (Scheffler 2003; Fourie 2012) and 'democratic equality' (Anderson 1999). While the exact requirements of relational equality have not yet been spelt out in much detail, ${ }^{2}$ the kinds of phenomena that relational approaches single out as problematic typically include hierarchies of certain kinds, oppression and stigmatisation of particular individuals or groups. ${ }^{3}$

$2 \quad$ For some discussion on this, see Tomlin (2014), Lippert-Rasmussen (2015).

3 For example, Anderson (2009, p. 132) notes that relational inequality 'consists in hierarchical social relations among people, organized along lines of group identity such as race, class, and gender. Relational inequality has several modes, including hierarchies of standing (where a group is denied standing to make complaints against another group, or to hold it accountable for its conduct), of command (where members of one group monopolize positions of authority, which they exercise over members of other groups), and of esteem (based on publicly dominant invidious comparisons of some groups with others).' 
While these accounts focus on relationships between individuals, other accounts (e.g. Pogge 2004; Schemmel 2012) focus on the actions of institutions and the relationship between government and citizens. Such accounts identify as problematic, for example, intentionally harmful treatment of individual citizens (or groups) by institutions. Although sometimes treated as distinct types of relational egalitarianism (e.g. Kelleher 2016), not all of the literature makes a clear distinction between these two sets of requirements. It is not clear how, precisely, relational egalitarians envision the relationship between, on the one hand, requirements concerning the relationships among citizens (or individuals more broadly) and, on the other, the constraints institutions must respect when dealing with citizens. In some accounts, it is the democratic nature of liberal states that seems to provide the link: to the extent that institutions are ultimately made up of individuals and, at least in democratic contexts, in some sense represent their citizens, the institutional and individual levels are clearly not independent. Anca Gheaus, for example, describes the 'relational features of a society' as 'how its members treat each other as citizens, either directly in personal interactions or through the mediation of social institutions' (Gheaus 2016, p. 55). For the purposes of this paper, I will assume that both the inter-individual and the institutional-individual levels as relevant for relational equality.

A second aspect of relational egalitarianism on which different interpretations are possible is the question of whether what matters is (a) how we act towards others, (b) which attitudes we have towards others, or (c) which attitudes we express. Relational egalitarians whose focus is on the relationships between individual citizens often describe their account in ways that leave open whether the primary focus is how citizens treat one another, how they think of one another, or both. This ambiguity is reflected, for example, in Miller's statement that his account of equality envisages 'the ideal of a society in which people regard and treat one another as equals' (Miller, 1997, p. 224, emphasis added).

For Anderson, all three criteria - equal treatment, equal regard and expressive concerns - seem to be requirements of relational equality. She considers hierarchies of esteem - 'whereby those on the top elicit honor and admiration, while those below are stigmatized and held in contempt as objects of ridicule, loathing, or disgust' (Anderson 2008, p. 263) - as inimical to social equality, suggesting that citizens' attitudes towards one another clearly fall within the remit of relational equality. Her account also requires that citizens meet certain standards of conduct when interacting with one another:

To stand as an equal before others in discussion means that one is entitled to participate, that others recognize an obligation to listen respectfully and respond to one's arguments, that no one need bow and scrape before others or represent themselves as inferior to others as a condition of having their claim heard. (Anderson 1999, p. 313) 
Similarly, in her account of racial inequality, she notes that 'the relational theory of inequality locates the causes of economic, political, and symbolic group inequalities in the relations (processes of interaction) between the groups' (Anderson 2010, p. 16) and defines 'a relation between two people as a mode of conduct - a practice or habit in accordance with a principle, rule, process, or norm - by which one party interacts with (or avoids) the other party, or acts in ways that affect the other party's interests or autonomy' (Anderson 2010, p. 17). She also endorses the idea that requirements about what one's actions express apply at the individual level (Anderson and Pildes 2000) and has described her account of equality as capturing 'the expressive demands of equal respect' (Anderson 1999, p. 289).

The division between egalitarian behaviour, actual attitudes and expressive concerns also applies when the locus of relational equality is taken to be the relationship between institutions and citizens. Thomas Pogge's account focuses on how institutions treat citizens. As he notes, 'a liberal society, or state, ought to treat all its citizens equally in terms of help and hindrances' (Pogge 2004, p. 147). While Schemmel's account similarly considers how institutions treat citizens, he also thinks of relational equality in terms of the attitudes that institutions express towards individuals (Schemmel 2012).

Distinguishing more clearly between attitudes and treatment, and between baving and expressing certain attitudes, reveals that we might end up with very different requirements of relational equality. Moreover, these three criteria need not pull in the same direction and can, in fact, come into tension with one another: ${ }^{4}$ Individuals can treat others as equals without regarding them as equals; for example, we might treat someone as an equal in the sense that we give their interests appropriate weight without actually thinking of them as our equal. ${ }^{5}$ Similarly, which attitudes one has towards others and which attitudes one expresses can come apart: we can, for example, use gender-neutral language, thereby expressing certain attitudes about gender equality, without actually having those attitudes.

$4 \quad$ Further divisions may be created by different interpretations of what kinds of attitudes and/or treatment are required by relational egalitarianism. For example, egalitarian attitudes may include an affective component (e.g. attitudes of care and solidarity; see Baker, 2015), or that we do not seek to avoid interaction with members of particular groups (Voigt 2017). The table therefore should not be taken to exhaust possible interpretations of relational egalitarianism.

$5 \quad$ See also Cohen (2014, p. 197). I'd like to thank Kasper Lippert-Rasmussen for his comments on this point. 
Table 1: What does relational equality require?

\begin{tabular}{|l|l|l|l|}
\hline & $\begin{array}{l}\text { Egalitarian behav- } \\
\text { iour (= treating oth- } \\
\text { ers as equals) }\end{array}$ & $\begin{array}{l}\text { Egalitarian attitudes } \\
\text { (= regarding others } \\
\text { as equals) }\end{array}$ & $\begin{array}{l}\text { Expressive require- } \\
\text { ments (= expressing } \\
\text { egalitarian attitudes) }\end{array}$ \\
\hline individual-individual & $\begin{array}{l}\text { Anderson } \\
\text { Fourie } \\
\text { Miller } \\
\text { Scheffler }\end{array}$ & $\begin{array}{l}\text { Anderson } \\
\text { Fourie } \\
\text { Miller } \\
\text { Scheffler }\end{array}$ & Anderson \\
\hline $\begin{array}{l}\text { institutional-individ- } \\
\text { ual }\end{array}$ & $\begin{array}{l}\text { Pogge } \\
\text { Schemmel }\end{array}$ & Pogge & $\begin{array}{l}\text { Anderson } \\
\text { Schemmel }\end{array}$ \\
\hline
\end{tabular}

The table above sets out these two distinctions and resulting six possibilities of how relational requirements might be understood. The table also indicates which philosophers seem to endorse particular requirements as part of their preferred conception of relational equality. ${ }^{6}$ The possibility of different interpretations does not, of course, undermine the relational project; it suggests, however, that we need greater clarity on which requirements individual relational egalitarians endorse (and do not endorse) and how any conflicts between competing requirements might be resolved.

\section{The expressive dimension of state action}

Among relational egalitarians, the idea of an expressive theory of state action has been developed in most detail by Anderson, in a paper co-authored with Richard Pildes (Anderson and Pildes, 2000). On the account they propose, an expressive theory of the law considers the attitudes that are 'implicit' in state action, such as particular pieces of legislation passed by the legislature. This, they suggest, is based on a broader understanding of expressive theory, which requires that we evaluate actions - individual and collective - 'in terms of how well they express certain intentions, attitudes or other mental states' (Anderson and Pildes 2000, p. 1508). ${ }^{7}$ The actions of the state, understood as a collective agent, must also meet such requirements. The idea of an expressive dimension of state action has also been discussed by other writers, primarily in the legal context and in relation to the justification of punishment and interpretation of the Equal Protection clause (Adler 2000a). In this paper, I focus primarily on Anderson and Pildes' and Schemmel's arguments since their accounts are clearly informed by relational egalitarian commitments but I also draw on other accounts where appropriate.

$6 \quad$ My understanding of these distinctions draws on, and informed by, Kelleher's (2016) even though I end up proposing a somewhat different categorisation.

$7 \quad$ Expressive meaning may inhere not only in state action but also in states' not acting. For example, a state's failing to alleviate poverty or social exclusion may be taken to have expressive meaning. It is plausible that trying to attribute meaning to failures to act would raise particular complexities that do not arise when what we are concerned with is actions. To my knowledge, expressive theorists have not considered this possibility. I'd like to thank Adam Swift and David O’Brien for alerting me to this possibility. 
What, then, are the intentions and attitudes that state action ought to express? Citing Dworkin (1977), Anderson and Pildes suggest that state action must express 'equal concern and respect' for all individuals. Moreover, state action must express 'a collective understanding of all citizens as equal members of the state, all equally part of “us", notwithstanding racial, ethnic, or religious differences' (p. 1520, emphasis omitted). ${ }^{8}$ By the same token, states must avoid actions that express the view that some individuals have lesser status when it comes to community membership.

While Anderson and Pildes do not explicitly connect their argument for such a theory with considerations of relational equality, their account of which attitudes state action must express reflects the commitments that also underlie relational egalitarianism and which Anderson has developed in her other work. They also describe a concern for the expressive dimension of state action as stemming from a broader commitment to the principle of equal concern and respect (Anderson and Pildes, 2000, p. 1570). Schemmel (2012, p. 143) connects the two accounts explicitly, noting that the attitudes expressed by institutions in their treatment of individuals and groups have intrinsic significance for justice. ... the development of a relational theory of equality on the basis of the expressive perspective is a worthwhile enterprise'.

Much of Anderson and Pildes' discussion focuses on attitudes towards different racial groups. Expressive theories single out as problematic state action that reflects attitudes of contempt or hostility towards particular racial groups or that makes race too salient by 'convey[ing] the message that political identity is, or should be, predominantly racial' (Anderson and Pildes 2000, p. 1539). One particular kind of expressive meaning that Anderson and Pildes discuss relates to the exclusion of those with particular conceptions of the good. Consider a policy that encourages the placement of Christian religious symbols on public property during Christmas time. Such a policy, they argue, may simply reflect a desire to express joy about Christmas. However, this policy (unwittingly) manifests a conception of the political community that is not inclusive of non-Christians:

Their [the legislators"] action... manifests their exclusive conception of the "we" with whom they are collectively celebrating. "We" only includes Christians. Non-Christians do not participate in "our" collective celebration, and thus are excluded from the legislators" concep-

\footnotetext{
8 Anderson and Pildes move without comment from 'all individuals' to 'citizens'. The question of the scope of relational egalitarianism and how it might be compatible with a cosmopolitan view about states and the membership in political communities strikes me as crucial; there has been some discussion of what a relational approach might apply at the global level; see Cloarec (2017), Nath (2014; 2015) and work-in-progress by Sara Amighetti. In the global justice literature, cosmopolitan views are sometimes contrasted with 'relational' views, which in this context refers to views that allow that individuals might have stronger duties to their compatriots than to members of other states. Hellman (2000) briefly touches on the question of whether expressive constraints might also apply when the attitudes expressed relate to non-citizens rather than citizens but does not go into much detail.
} 
tion of who "we" are. The legislators fail to acknowledge the insider status of non-Christians in a context that demands such acknowledgement, and thereby withdraw from nonChristians the social status of fully included citizens. (Anderson and Pildes 2000, p. 1550)

This example is interesting not least because of its clear continuities with the debate about liberal neutrality. From the perspective of liberal neutrality, the primary concern about such a policy would be that by endorsing (or relying on arguments that implicitly endorse) a particular religious view, the state fails to be neutral between different conceptions of the good. Just as with Anderson and Pildes' expressive theory, such concerns are grounded in a recognition of the equal status of individuals and the constraints that this equality imposes on the grounds on which it is legitimate for states to act (Rawls 1996). While from both of these perspectives, endorsement of comprehensive conceptions of the good is problematic, the concern from an expressive perspective is that such endorsement signals the attitude that those who do not share the comprehensive views in question are not full and equal members of the community. ${ }^{9}$

Expressive considerations, Anderson and Pildes argue, are, of course, not the only criterion by which state action should be assessed. But on their account expressive considerations impose constraints on permissible actions: they require that we assess particular actions with respect to whether they express 'morally right attitudes' towards individuals. Such concerns require that we be critical of the kinds of reasons and justifications that support particular policies: 'expressive norms regulate actions by regulating the acceptable justifications for doing them' (Anderson and Pildes 2000, p. 1511, emphasis omitted).

Schemmel's account relies on Anderson and Pildes' in developing the idea of an expressive dimension of institutional action. As noted above, he ties the expressive dimension of state action closely to what it means for institutions to treat citizens as equals, noting that 'what is primarily justice relevant about the way institutions treat people is the attitude towards individuals and groups that is expressed in institutional action' (Schemmel 2012, p. 124). Schemmel draws on Pogge's 'V example', in which Pogge describes six different scenarios, all of which involve some individuals lacking a particular nutrient, V. The mechanisms through which this deficiency comes about differ across the scenarios. In scenario 1, for example, it is 'officially mandated' by the state; in scenario 3, 'social institutions foreseeably and avoidably engender (but do not specifically require or authorize)' the deficit; in the final

$9 \quad$ State action may also have the goal of preventing citizens from engaging in forms of expression that predictably result in other citizens feeling that they are not full members of the community. For example, Parekh notes that the German constitutional court upheld legislation making Holocaust denial illegal because Holocaust denial created a 'social and political environment in which [German Jews] cannot feel an integral part of the German society’ (Parekh 2006, p. 215). 
scenario the deficiency results from the affected individuals' own choices and the state does not seek to address it (Pogge 2004, pp. 156-157, emphasis in original). Schemmel highlights that the relevant difference between the scenarios is the different institutional attitudes expressed: our intuitive assessment of the relative injustice involved in the different scenarios, he suggests, is based on the different institutional attitudes - such as hostility, contempt or neglect - they express:

The different scenarios ... present different implicit institutional judgements about the worth of those disadvantaged, and the claim is that, other things being equal, our different intuitive reactions to the different scenarios rest on our perception of these judgements. In each such case, social hierarchies are instantiated or made possible by such implicit judgements of worth, and this is what the relational egalitarian primarily objects to. (Schemmel 2012, p. 134)

Like Anderson and Pildes, Schemmel emphasises that the expressive content of state action is conceptually distinct from its outcomes: that is, expressive concerns about state action are independent of concerns about the consequences that expressively problematic state action actually has (though the anticipated consequences of particular actions can also shape their expressive content). As I discuss in more detail in the next section, Schemmel takes a somewhat different position on how to determine the meaning of particular institutional actions from Anderson and Pildes; his account gives a greater role to the actual attitudes of the agents responsible for the action than Anderson and Pildes do.

\section{Determining the expressive meaning of state action}

Expressive theories seek to identify the expressive content of particular policies and assess whether that content is consistent with a view of all individuals as equals and the idea of an inclusive, egalitarian community. While the accounts offered by Anderson, Pildes and Schemmel provide a general outline of the kinds of questions an expressive theory of state action might ask and suggest some examples of how specific legislation may become problematic from this perspective, how exactly these kinds of considerations can be extended to other forms of state action is far from obvious. Answering this question is important, not least because the extent to which we ought to care about this dimension of state action hinges on how exactly it is specified.

Anderson and Pildes reject two reasons why we ought to care about the expressive dimension of state action: the harm it causes and the actual attitudes it reflects; Schemmel agrees that expressive concerns are not about consequences but seems more open than Anderson and Pildes to the idea that the expressive meaning of state action depends in part on how the action is perceived. Anderson and Pildes' approach allows them to identify a broader range of actions as expressively problematic than would be possible on an account that relies on harm and actual attitudes but it also detaches their 
account from two intuitively compelling reasons to be concerned about problematic expression. I suggest in this section that the expressive dimension should be tied more closely to actual inegalitarian attitudes as well as the speakers' intentions than Anderson and Pildes propose.

\section{Expression vs. outcomes: what's the harm of 'expressive harms'?}

Anderson and Pildes argue that the concern with the expressive dimension of state action is not motivated by a concern for its effects. For an action to express the right kinds of attitudes towards others, Anderson and Pildes explain, its authors must have taken the likely consequences into account (Anderson and Pildes 2000, pp. 1513-4). It is less clear, however, how an action's actual consequences affect its expressive meaning. At various points in their paper, Anderson and Pildes emphasise that what gives an action problematic meaning is not its consequences. They describe expressive harms as

harms inherent in the principle on which the laws are enacted, rather than in the causal consequences of the laws. Policies adopted out of contempt or hostility towards a racial group, or with the purpose of branding a racial group as inferior, are expressively harmful ... regardless of their direct material, social, and psychological consequences. (Anderson and Pildes 2000, p. 1542) ${ }^{10}$

Thus, even though the assessment of an action's expressive content must rely (at least in part) on an assessment of how the action's author took into account its likely consequences, the action's actual consequences should not affect our assessment of its expressive content. This is because, Anderson and Pildes explain, 'legal communications of status inferiority constitute their targets as secondclass citizens' (p. 1544). A legislator may put in place a law precisely because she wants a particular group to suffer, say for racist reasons. The expressive content of that law would, on this account, remain the same even if the law, for reasons the legislator was not aware of, actually leads to positive consequences for that group. Schemmel agrees with Anderson and Pildes on this point, noting that

Legal discrimination against a group ... constitutes a particular kind of objectionable inegalitarian relationship between the state (or 'us with our citizens' hats on') and the members of that group: the assignment of inferior legal status. Even if it will regularly happen, in the case of a generally effective legal system, that such laws lead to overall social inferiority of the members of the group in question, because other individuals and groups take them as reasons to treat them in objectionable ways, this need not be the case for them to be unjust. They would not cease to be unjust even if their targets experienced a boost in self-esteem, for example, due to their solidarity in indignation. (Schemmel 2012, pp. 140-141, emphasis in original) 
To the extent that legislation with problematic expressive content typically also creates substantive harms for people, this distinction may not matter much in practice. However, at least theoretically, expression can be problematic independently of any substantive harms that it creates. This is consistent with the idea that expressive concerns are to be understood as non-consequentialist. ${ }^{11}$ On this approach, it would be more appropriate to describe the concern as an expressive wrong rather than an expressive harm. $^{12}$

At various points in their paper, however, Anderson and Pildes do seem to be concerned with the effects resulting from what actions express. ${ }^{13}$ They note, for example, that 'a person suffers when she is treated according to principles that express negative or inappropriate attitudes towards her' (p. 1527, emphasis added). In this description, the relevant harm results from the meaning of the action: it is because (and to the extent that) individuals understand the expressive meaning of an action that they are harmed by it.

This captures a rather different idea of expressive harm, which focuses on its consequences. Arguably, part of what makes an expressive theory of state action attractive is that it can capture a particular kind of harm: the harmful effects of being the target of disparaging attitudes. The actions of individuals or groups can harm in ways that go beyond the actions' direct effects. Importantly, such harms can also affect a group of individuals much larger than those directly affected by the actions. For example, while the recent North Carolina bathroom laws have a direct impact on transgender people in North Carolina, the harm associated with being the target of disparaging attitudes can be experienced by all transgender people, not only those who live in North Carolina.

Moreover, the harms might involve not just effects on individuals but broader societal consequences as well, as Pildes and Niemi explain:

The harm is not concrete to particular individuals, singled out for distinct burdens. The harm instead lies in the disruption to constitutionally underwritten public understandings about the appropriate structure of values in some arena of public action. Expressive harms are therefore, in general, social rather than individual. Their primary effect is not as much the tangible burdens they impose on particular individuals, but the way in which they undermine collective understandings. (Pildes and Niemi 1993, p. 507) 14 $^{14}$

11 For discussion along these lines, see also Altman (1999, p. 79) and Pildes and Anderson (1990, p. 2144).

12 Indeed, Altman (1993) describes the expressive harm he associates with hate speech as 'speech-act wrong' even though he subsequently abandons this language and refers to expressive harms instead (Altman 2002).

13 This ambiguity in Anderson and Pildes' account is also pointed out by Adler (2000b).

14 With a similar focus on how state action can affect social norms, Sunstein's (1995) account of the expressive dimension of the law focuses on how laws can be designed so as to change social norms. In this respect, he thinks of the expressive dimension of state action in rather different terms. 
Within the context of a relational egalitarian account we might be particularly worried about the impact that the meaning of state action has on citizens' attitudes: for example, policies that express racist attitudes can serve to normalise and reinforce these attitudes among citizens. This concern, of course, reflects other commitments of relational equality. To my mind, the effects of particular expressions on individuals as well as on attitudes more broadly - do play an important role in motivating our concern for the expressive dimension of state action. However, these effects are best captured separately from the action's problematic content - for example as part of a distributive account that captures these effects on individuals as part of the equalisandum - and should not be understood as the reason why the expressive content of a particular action is problematic: a sign that indicates that a swimming pool is for white people only would have problematic expressive meaning even if no one saw the sign and it had no effects whatsoever. ${ }^{15}$

Detaching the expressive meaning of particular actions from their effects also opens up the possibility that a policy may be problematic from an expressive perspective while at the same time promoting other aspects of relational equality. This highlights the possible tension between expressive considerations and other requirements of relational equality, such as those of equal regard among citizens. At least in principle, there could be policies that are expressively problematic but enhance other aspects of relational equality. Consider the following (admittedly, unlikely) scenario. A law is passed that requires segregation of different ethnic groups in public spaces, expressing problematic views about racial equality. However, the population oppose the policy (and its implicit meaning) and respond with solidarity across racial boundaries, leading ultimately to more egalitarian relationships among members of different groups. In practice, of course, problematic expression is likely to undermine egalitarian relationships but this is not necessarily so and, at least conceptually, different requirements of relational equality can come apart, making it necessary to balance competing considerations against one another. This also casts doubt on the argument that one of the advantages of a purely relational over a pluralist view of equality is that it does not require balancing of different considerations (Schemmel 2012). Relational egalitarians, then, may have to find ways to address conflicts between different sets of requirements of relational equality.

\section{How do we determine a state action's expressive content?}

If relational egalitarians such as Schemmel, Anderson and Pildes are not primarily concerned with the consequences of problematic expression, what else could motivate their accounts? Considering their

15 For related discussion of a similar example, see Wolff (2000). 
account of how we can identify the meaning of specific actions can help us make progress on this question. Anderson and Pildes emphasise, first, that actions can express attitudes that the author of the action does not in fact have: just as a musician can play a piece of music that expresses sadness without herself feeling sad, state action can express attitudes that the individual(s) driving the action do not, in fact, share. Similarly, imagine a lawmaker who passes a law that denies blacks the right to vote. This law, they suggest, expresses contempt for blacks even if the lawmakers themselves do not have such contempt and are implementing the law merely to pander to their racist constituents (Anderson and Pildes 2000, p. 1508). Schemmel agrees that institutions can have beliefs and intentions that are not shared by any of its members (Schemmel 2012, pp. 135-136).

However, it does not follow that the lawmakers' actual attitudes should make no difference to our assessment of what the law expresses. It seems that the expressive meaning of the law would be different (and more problematic) if the lawmakers did in fact have the same contempt for blacks as their constituents. Similarly, if we knew that the lawmakers had contempt for the racist attitudes of their constituents but felt that the law passed was the only way to prevent greater harms to the black community, the law would arguably take on a different expressive meaning again. This is not to say, of course, that in the situation Anderson and Pildes describe, the law is not expressively problematic the actual attitudes the lawmakers have (their willingness to pass a law restricting the political rights of blacks so as to ensure their own political power) are certainly problematic: they reflect a failure to give appropriate weight to the interests of their black constituents and basic requirements of political equality. (As I will suggest in the next section, this kind of failure is one, very important, way in which state action can become problematic from an expressive perspective.) If this is right, then we must give a greater role to the actual attitudes of the agents in question than Anderson and Pildes allow.

A second aspect of Anderson and Pildes' account (on which Schemmel seems to disagree) is that, for them, the meaning of an action does not depend on the agents' intentions: intentions matter but are 'not the sole determinants of what attitudes their actions express' (p. 1513). ${ }^{16}$ In order for an action to express the right kinds of attitudes, then, it is not so much that its author must intend to express particular attitudes. Rather, our assessment of what actions mean must be based on objective criteria: we must determine the 'public meaning' of these actions (Anderson \& Pildes 2000, p. 1524).

16 Anderson and Pildes also note: 'An agent's sincerely avowed purposes are not the sole determinants of what her actions mean. Expressive theories of action hold people accountable for the public meanings of their actions. This is true of collective actors as well, as legal doctrine already recognises. The articulated reasons of legislators can be relevant in determining whether a state law expresses impermissible purposes or values, but ultimately it is a question of law, and hence of external normative judgement, whether the state action does indeed express impermissible purposes or values' (2000, p. 1513). 
This public meaning can deviate from the agents' intended meaning when, for example, they act 'negligently or thoughtlessly, failing to notice or take certain considerations as reasons for action' (Anderson \& Pildes 2000, p. 1512). People may also inadvertently engage in actions with problematic expressive content, for example when they are ignorant of particular social conventions or act on assumptions of which they are unaware (Anderson \& Pildes, 2000, p. 1513).

Thinking about the expressive dimension of state action along these lines makes it possible to identify as problematic state action that reflects legislators' unconscious biases, thoughtlessness or lack of awareness of the possible consequences of particular policies. This is particularly relevant for the purposes of this paper because public policies are often well-intentioned and motivated by a desire to improve particular outcomes. If we assume that actual intentions do not determine the expressive content of state action, then even well-intentioned policies, such as those discussed in the next section, can be problematic for expressive reasons.

However, it seems plausible that intentions play a greater role in shaping the expressive meaning of an action than Anderson and Pildes allow. Consider, for example, the recent tennis match at which the US host welcomed the German team by playing the first stanza of the 'Deutschlandlied' rather than the third stanza, which is the official German national anthem. With its lyrics calling for 'Germany above everything in the world' and describing the country's borders as containing parts of Poland, France, Russia and various other countries, the first stanza was frequently played in Nazi Germany. Given its association with Nazi Germany and the content of the lyrics, the first stanza is now taken as an endorsement of extreme right-wing and neo-Nazi views. Members of the German team were appalled, and the tennis association issued an apology, stating that they had made a mistake.

What Anderson and Pildes' account would seem to focus on is the meaning of the first verse, which remains unaffected by whether or not those who played it intended to express extreme rightwing views. However, if the verse was played as a genuine mistake and out of lack of awareness of its meaning, this should, I think, affect our assessment of the expressive meaning of their choice of anthem. As it stands, Anderson and Pildes' approach would suggest that we focus on the meaning of the verse and pay only little attention to what the agent in question intended to express. But intentions, it seems, make a crucial difference here; without taking intentions into account, we cannot distinguish between the tennis association's gaffe and a neo-Nazi's singing the first verse of the anthem, fully 
aware of, and endorsing, its meaning. ${ }^{17}$ This suggests that intentions can make much more difference to the expressive meaning of actions than Anderson and Pildes suggest.

This is not to say, of course, that actions cannot be expressively problematic unless the agent is intending to express a problematic attitude. Actions can be expressively problematic even if the intention is to express an attitude that strikes the speaker as unproblematic. Even if, for example, a catcaller genuinely intends to compliment a female passer-by rather than express a problematic attitude towards women, this does not make the cat-calling unproblematic. Similarly, asking a person of colour where they're from can convey the implicit assumption that only white people can be local, even if the speaker only intended to express friendly curiosity. Nonetheless, it seems that if the cat-caller intended to express disrespect and if the 'where are you from?' question were motivated by a desire to make the interlocutor feel unwelcome, this would change the expressive meaning of each situation. The expressive meaning of the actions in question is problematic in all four cases, but we would, it seems, miss important differences between the scenarios if we failed to take the agents' intentions into account.

Rather than relying on intentions or actual attitudes, Anderson and Pildes emphasise that their expressive theory is concerned with the 'public meaning' (p. 1512) of particular actions. They further explain that the interpretation of what a particular action means must make sense in light of the community's practices more broadly, its history and shared meanings. This might suggest that as part of the process of determining what a particular action expresses, we have to consider how it is actually perceived, for example by the citizens most affected, or by the public as a whole. However, Anderson and Pildes reject this view: 'The public meaning of an action is not even determined by shared understandings of what the action means' (2000, p. 1524). For example, they suggest, it was insulting to women for male colleagues to comment on their appearance in the workplace even before such comments were generally recognised as problematic. They argue:

The expressive meaning of a particular act or practice need not be in the agent's head, the recipient's head, or even in the heads of the general public. Expressive meanings are socially constructed. These meanings are a result of the ways in which actions fit with (or fail to fit with) other meaningful norms and practices in the community. Although these meanings do not actually have to be recognised by the community, they have to be recognisable by it, if people were to exercise enough interpretive self-scrutiny. This is the sense in which expressive meanings are public constructions. ... a proposed interpretation must make sense in light of the community's other practices, its history and shared meanings. Thus,

17 Schemmel (2012, p. 139) seems to anticipate a similar concern in relation to what he calls the 'collective communication of attitudes': when a non-native speaker mistakenly apologises to rather than blames her interlocutor because she has confused the relevant words, we would not want to say that she has in fact apologised. 
to grasp the expressive meaning of an act, we try to make sense of it by fitting it into an interpretive context. ... The expressive meaning of a norm does not inhere in that norm in isolation, but is a product of interpreting the norm in the full context in which it is adopted and implemented. (Anderson and Pildes 2000, p. 1525)

Thus, a state action can be considered to have objectionable expressive content even if it is not recognised as problematic by the community. While the interpretation of an action's expressive content must make sense in light of the community's norms and practices, it does not require that members of that community actually perceive the action as problematic.

Again, this move means that a broader set of actions can become problematic from an expressive perspective than if we relied on actual perceptions to determine expressive content. It is not clear, however, how such an expansive account would accommodate the idea that actual perceptions (and intentions) can change the meaning of particular actions. If the primary focus is on what is 'recognisable', independent of how people actually interpret particular actions, this may fail to capture a crucial aspect of what an action means. Consider the gender division of public washrooms. In the literature on the expressive content of the law, this division is contrasted with racial segregation of public spaces to explain what makes racial segregation, but not the gender division of toilet facilities, problematic from an expressive perspective. For example, Hellman notes that although single-sex washrooms discriminate on the basis of sex, they do not violate expressive requirements because their meaning is 'innocuous': 'while there is expressive content to this practice, perhaps that certain bodily functions ought to be kept private from the opposite sex, this meaning does not imply less regard for one sex or the other' (Hellman, 2000, p. 15).

Of course, we have become much more sensitive to how assumptions about gender and the division of facilities according to biological sex are problematic and would probably be less quick in describing the expressive content of laws on gender-specific facilities as unproblematic. Changes in our awareness about what equality might require could affect how quickly we in fact recognise the problematic expressive content of particular laws. On Anderson and Pildes' account, the primary question would be whether these concerns are recognisable in a particular interpretive context. This means that we would have to ask whether, for example, in 2000, when Hellman published her article, the problematic aspects of single-sex bathrooms would have been 'recognisable'.

However, irrespective of whether these concerns would have been recognisable then, the growing recognition of these issues has arguably also changed the meaning of particular actions. For an institution or lawmaker to insist on gender-specific bathrooms now arguably has a very different meaning than it did fifteen years ago, before the proliferation of transgender issues. Similarly, whereas 
fifteen years ago, a unisex washroom may not have been imbued with any particular meaning, they are now often installed precisely so as to express solidarity with transgender people and a rejection of discriminatory attitudes, with signs indicating, for example, that washrooms are 'gender neutral', 'gender inclusive', 'all welcome', etc. Among the actions that are recognisable as problematic within a particular interpretive context, then, there may well be differences in meaning as a result of how such actions are actually understood. It is not clear that Anderson and Pildes' account would allow us to capture these complexities.

The reason these differences should, I think, affect our judgement about what the action expresses is that, as already noted earlier, the actions reflect very different attitudes on the part of the agents. While the problems around gender-specific washrooms would have been recognisable fifteen years ago, installing such facilities then vs. now arguably reflects very different attitudes. Insisting on gender-specific washrooms now seems to reflect attitudes of contempt towards transgender people, or at least indifference towards, or lack of concern for, their interests. We would miss an important dimension of what these actions mean if we were to exclude these differences from our assessment. Again, then, this suggests that the expressive account is more compelling if it is tied more closely to the reflection of actual inegalitarian attitudes.

This can also be expressed in terms of equal treatment, which is one of the other core requirements of relational equality: to treat someone as an equal, we must - among other things - express the appropriate attitudes towards them. ${ }^{18}$ In fact, it seems that part of the reason Schemmel does not make a clear distinction between considerations of equal treatment and expressive requirements is that he thinks that expressing appropriate attitudes is part of what it means for the state to treat its citizens as equals. Importantly, however, treating someone as an equal requires more than just the expression of appropriate attitudes.

This section has suggested a somewhat different interpretation of the expressive dimension of state action than is currently proposed in the literature. First, I agree with Anderson, Pildes and Schemmel that the expressive dimension of state action is best thought of as a deontological constraint that is independent of the consequences of particular actions. While it is also important to keep in mind that being the target of disparaging attitudes can clearly have significant, harmful effects on individuals, especially when these attitudes are expressed by institutions, these harms need not be captured as part of the expressive account and might be better captured via an appropriate distributive

18 The link between the expression of disparaging attitudes and unequal treatment is also implicit in Altman's account of hate speech (Altman 1993; 2002). 
account. Second, contra Anderson and Pildes as well as Schemmel, I suggested that the actual attitudes of agents should play a more important role in determining the expressive meaning of actions. Importantly, relevant inegalitarian attitudes can include not just contempt for certain individuals or groups but also indifference or blindness to their concerns and an unwillingness to give appropriate weight to their interests. Finally, contra Anderson and Pildes but in line with Schemmel's account, I argued that agents' intentions also play an important role in assessing the expressive meaning of state action. More broadly, we can understand the expression of disparaging attitudes as a particular kind of unequal treatment: by expressing such attitudes, the state treats some of its citizens as less than equal. This unequal treatment is conceptually independent of any harmful effects experienced by the citizens in question.

\section{The expressive meaning of public policy: how things can go wrong}

Having explored how we can identify and assess the expressive dimension of state action, in this section I suggest different ways in which particular policies or other kinds of state action can become problematic from an expressive perspective. I consider what specific attitudes state action might express that would be problematic, illustrating these with real-world examples. The current literature is primarily concerned with expressive considerations in the context of legislation and focuses for the most part on legislation that signals exclusion of citizens from ethnic and religious minorities (e.g. legislation that permits racial segregation on trains). However, in principle all state action, including different kinds of public policy, can (and should) be evaluated with respect to its expressive content.

\section{1 (Un)equal membership}

First, one of the problematic 'meanings' of state action that Anderson and Pildes identify as inconsistent with the expression of equal concern and respect relates to messages that signal unequal membership and, at worst, exclusion of some members of the community. By the same token, certain actions and provisions offered by the state can help express the equal status of all citizens as full members of the community.

\section{(a) Legitimising exclusion from benefits}

Arguments along these lines could be used to argue for the public provision of social services. Consider health care. In her 1999 paper, Anderson considers the implications of different perceptions of equality for the provision of health care by asking what proponents of different egalitarian views might say to an individual who had not purchased health insurance but now needed medical treatment. 
While, according to Anderson, a luck egalitarian would tell this person, 'You are too stupid to run your own life', someone committed to the relational egalitarian account Anderson favours would say the following:

You have a moral worth that no one can disregard. We recognize this worth in your inalienable right to our aid in an emergency. You are free to refuse this aid once we offer it. But this freedom does not absolve you of the obligation to come to the aid of others when their health needs are urgent. Since this is an obligation we all owe to our fellow citizens, everyone shall be taxed for this good, which we shall provide to everyone. This is part of your rightful claim as an equal citizen. (Anderson 1999, pp. 330-331, emphasis added)

Having juxtaposed these two very different attitudes toward those who fail to purchase health insurance, she asks, rhetorically, 'Which rationale for providing health insurance better expresses respect for its recipients?' (Anderson 1999, pp. 331, emphasis added). Similarly, Daniel Weinstock has suggested explicitly that health care provision matters, not just because of its direct effects on health outcomes but also because of its meaning:

health care matters to us not because of what it does but because of what it means. Above and beyond the benefits that individuals accrue, health care has come to matter to people because it betokens the extent to which they are treated as deserving of equal care and respect. The social meaning of health care is tied in with our sense of ourselves as equal citizens in ways that other goods (say education) are not, even if for any objective construal, other goods matter just as much, perhaps even more, than health care per se. (Weinstock 2011, p. 429) ${ }^{19}$

While this leaves open how precisely the health care system must be designed, the requirement not to express attitudes of exclusion and unequal membership may rule out certain ways of providing health care. For instance, from this perspective it will be problematic if policy or legislation allows some members of the community to lose access to particular benefits: the West Virginia Medicaid regulations under which recipients could lose access to basic services such as mental health care if they failed to meet certain requirements (attending appointments, following doctors' orders, etc.) comes to mind as a recent example. ${ }^{20}$

Similarly, two-tier healthcare systems, in which some citizens have private insurance that affords them access to better services and/or allows them to skip queues for existing services, could be seen as signalling to individuals who can only afford the basic services that they are not in the same

19 As Landes and Néron (2015, p. 149) suggest, this line of argument can be applied to social insurance schemes more broadly: 'Public insurance schemes ... create specific moral relations among individuals and can potentially send a powerful message of equality.'

20 For discussion of this case, see Bishop and Brodkey (2006), Daniels (2011), Voigt (2012a). 
boat' as their better-off peers. ${ }^{21}$ More broadly, legislation that permits such systems can communicate ideas about unequal membership, in the sense that it communicates a state's willingness to allow some citizens to be excluded from services that are available to those who can afford to pay (or pay more) for them.

In addition to whatever expressive concerns we can identify, two-tiered health care systems might of course also be problematic from a relational perspective in a much more direct way. Such concerns include that such health care systems entrench status divisions among citizens or prevent them from thinking of each other as 'in the same boat' (Fourie 2016). A concern about the effects of particular health care arrangements on the relationships among citizens is distinct from expressive concerns to the extent that the latter focus on the meanings implicit in the state action permitting these kinds of arrangements rather than the actual effects of such arrangements: we can object to the expressive content of a policy that permits a two-tiered health care system even if such a health care system does not, as a matter of fact, undermine egalitarian relationships-for example because citizens are relational egalitarians and, for that reason, do not purchase private insurance.

A similar example of expressive content that signals that some people are not equal members of the community might be policies that exclude (or permit employers to exclude) from employment people who engage in certain behaviours. For example, a number of US employers (primarily hospitals) and also the World Health Organisation have recently adopted policies that exclude smokers from employment. ${ }^{22}$ These policies could be taken to express disparaging attitudes about smokers and for that reason become problematic from an expressive perspective. ${ }^{23}$ Even when such policies are implemented by private companies rather than state actors, the failure of governments to legislate against them could be seen as problematic from an expressive perspective in the sense that states fail to protect citizens against disparaging discrimination on the part of private employers. States' failure to prohibit such policies could then be seen as signalling unequal concern and a willingness for some of its citizens to be excluded from employment.

Mirroring concerns about policies that signal a willingness to exclude some members of the community, Hellman (2000) explicitly discusses the question of whether governments may adopt policies that prevent municipalities from providing anti-discrimination protection for smokers, where the

$21 \quad$ For a discussion of some of these issues as they have recently arisen in the New Zealand context, see Fenton (2013).

22 For discussion of such policies, see Asch et al. (2013), Schmidt et al. (2013), Voigt (2012b).

23 Lippert-Rasmussen (2014) discusses a relevant interpretation of discrimination as precisely this kind of 'objectivemeaning account' of discrimination. 
motivation underlying such policies would be to express disapproval of smoking. Hellman thinks that it is permissible for government to take a position on what is good or valuable, including the view that 'health is of greater value than the pleasure associated with smoking' (Hellman, 2000, p. 61). The government may endorse a particular conception of what a good life requires, Hellman argues, because 'the attempt to persuade itself acknowledges the equal worth of those with whom one disagrees' (Hellman, 2000, p. 61)..$^{24}$ However, for Hellman, things become problematic when, in expressing such views, states go so far as to 'expel non-adherents from the conversation' (p. 61). This would leave smokers without recourse if they are denied employment or housing. This legislation, Hellman argues, allows society to shun a person in order to change their behaviour: 'These amendments invite shunning in that they condone acts of private individuals who refuse to hire and rent or sell property, etc., to the persons identified' (Hellman, 2000, p. 61). Hellman concludes that the state 'may not condone the shunning of smokers by inviting individuals to avoid all contact with them. To do so expresses the view that smokers ought not to be participants in our ongoing conversations about what is of value. This denies them equal concern' (Hellman 2000, p. 63, emphasis added).

Importantly, as I noted in relation to two-tiered health care systems above, legislation that condones this kind of exclusion would be problematic from an expressive perspective even if it does not, in fact, lead to actual exclusion - for example if employers would not, in fact, seek to exclude smokers from employment. The expressive content of state action can be problematic irrespective of its actual effects.

\section{(b) Unequal membership of those with diverging views}

A somewhat different kind of exclusion from full and equal membership in the community may also be relevant here. One of Anderson and Pildes' examples is that of the display of Christian symbols in public spaces. While this kind of example picks up many of the concerns that political liberals have emphasised (i.e. a concern about the state endorsing particular conceptions of the good and thereby failing to comply with requirements of liberal neutrality), the concern for Anderson and Pildes is somewhat different: they note that such a policy is problematic from an expressive perspective because it signals that some citizens are excluded from full membership in the community: permitting public spaces to be used for the expression of (particular) religious beliefs expresses the attitude that those who do not share those beliefs are not full and equal members of the community.

$24 \quad$ Many political liberals would of course balk at the idea that it is permissible for states to endorse particular conceptions of the good; I will leave this concern to the side for now. Hellman here also seems to deviate from the interpretation of exclusion presented in the next sub-section. 
Something similar might happen with government campaigns that seek to encourage particular behaviours. Such campaigns often implicitly assume views about the relative priority of different values. While this does not necessarily amount to endorsing a full conception of the good, such views would be inconsistent with conceptions of the good that assume a different ranking of the relevant values or goals. $^{25}$

Consider breastfeeding. Many government agencies now recommend that mothers breastfeed exclusively (i.e. without the addition of other food) for six months. In a 2000 report published by the US Department of Health and Human Services (DHHS), the Surgeon General described low breastfeeding rates as a 'public health challenge' and recommended the introduction of 'national, culturally appropriate strategies to promote breastfeeding' (Department of Health and Human Services 2000, p. 3). The report also noted that 'the breastfed infant is the reference or normative model against which all alternative feeding methods must be measured with regard to growth, health, development, and all other short- and long-term outcomes' (Department of Health and Human Services 2000, p. 8). ${ }^{26}$

Given the insistence on breastfeeding, we might expect its benefits to be substantial and wellestablished. However, the evidence on which the Surgeon General Report bases its recommendations suggests benefits of moderate magnitude. The DHHS publication includes a list of 'excess health risks associated with not breastfeeding'. This includes increased risk of conditions such as ear infections, diarrhoea, asthma, obesity and sudden infant death syndrome. Of these conditions, only three have excess risks of $100 \%$ or higher (i.e. the condition is twice as likely in breastfed infants than it is in infants who are not breastfed): acute ear infection (100\%), diarrhoea and vomiting (178\%) and hospitalisation for lower respiratory tract infections (257\%). The report also lists a number of very

25 I assume here that Anderson and Pildes' argument on this issue applies to states' endorsement of comprehensive conceptions of the good more broadly, not just religious views. Some of the literature seems to treat religious views as relevantly different from non-religious comprehensive conceptions of the good (e.g. Hellman 2000). This is perhaps related to the fact that endorsement of religious views, but not endorsement of comprehensive conceptions of the good in general, is singled out by US legislation. However, for the purposes of the argument here, there is no relevant difference between religious and non-religious views.

26 This last statement illustrates an assumption implicit in this and other campaigns and policy documents: that exclusive breastfeeding is the 'baseline' while failing to comply with these recommendations (e.g. by not breastfeeding exclusively for the full six months, or not at all) amounts to exposing one's child to unnecessary risk and potential harm. This is exemplified particularly well by a media campaign that was initiated by the DHHS around the same time, which portrays pregnant women log rolling and riding a mechanical bull, with the tagline, 'You wouldn't expose your child to risks before it's born, why start after? Breastfeed exclusively for six months.' See Kukla (2006) for more detailed discussion of this campaign. 
severe conditions (e.g. sudden infant death syndrome, T2D, leukaemia) but the associated excess risk is below $60 \%$ in each case. ${ }^{27}$

These risks are presented in relative terms only, with no indication of the relevant absolute risks. While this is common in public health debates, it prevents readers (and, indeed, policymakers) from making the kind of full assessment of the actual risks and benefits on which decisions or recommendations regarding breastfeeding should be based. A particular risk factor may lead to a substantial increase in relative risk but if the absolute risk is tiny to begin with, then the absolute risk associated with the behaviour will still be fairly small. For example, if the baseline risk for a particular condition is 1 in 1,000,000, then a four-fold increase in relative risk (excess risk of 300\%) results in an absolute risk (4 in 1,000,000) that is still pretty small. Relative risk information on its own is insufficient for assessment of the relative risks and benefits. ${ }^{28}$

Finally, the report also notes that the evidence on which these numbers are based comes from observational studies and that therefore we cannot be certain that there is in fact a causal link between breastfeeding and the observed changes in risks for various conditions. Observational studies can provide information about associations but they do not allow conclusions about causation. However, this fairly important piece of information does not seem to affect the recommendations made.

How might this report become problematic from an expressive perspective? Arguably, the evidence presented in the report would suggest that the benefits of breastfeeding are, at least in the context of high-income countries, ${ }^{29}$ neither sufficiently substantial nor sufficiently certain to allow the conclusion that mothers must breastfeed. Given the uncertainties surrounding the benefits of breastfeeding, the firm conclusions offered in this report seem misplaced. In light of the costs and/or burdens that breastfeeding can impose on women (in terms of employment, personal costs, parenting

$27 \quad$ The empirical evidence regarding breastfeeding has likely changed since the publication of this report. For my purposes in this paper, the concern is the relationship between the recommendations issued in the report and the evidence on which they are based.

28 The way the evidence is presented also has significant potential to mislead readers. It is striking that the report describes excess risk associated with not breastfeeding as percentages - e.g. $47 \%$ for developing eczema - rather than saying that children who are not breastfed are 1.47 times as likely as children who are breastfed to develop eczema. The latter is arguably more intuitive but also means much smaller absolute numbers. Presenting the data as excess risks could lead audiences to overestimate the risks and thus make them more amenable to the conclusion the report seeks to draw.

$29 \quad$ Breastfeeding is an important concern in global health and the World Health Organisation has been prominent in encouraging breastfeeding across the world. However, the relative benefits of breastfeeding vary substantially depending on context, especially on whether there is access to clean water with which to prepare formula. For the purposes of this paper, I focus on breastfeeding recommendations issued in wealthy countries, where clean water is easily accessible and children could be fed formula without the risks associated with water contamination. 
arrangements, physical discomfort, etc.), it seems completely reasonable that there should be disagreement about whether or not women (in general and individually) should breastfeed. While there is some acknowledgement that it may be difficult for women to meet the breastfeeding recommendation (e.g. that employers may not be prepared to accommodate women who breastfeed), these are not taken as reasons that could legitimately lead women to decide against breastfeeding.

If disagreement about what, exactly, would be required of mothers in this context is reasonable, then insisting on a particular level of breastfeeding as the 'normative standard' could be taken to signal exclusion of those who disagree with the stated recommendations and its underlying assumptions. Similarly, when campaigns describe a decision not to breastfeed as part of a 'public health challenge' or as exposing children to unnecessary risks, this could be taken to signal exclusion of those mothers who either cannot breastfeed (e.g. for medical reasons) or - similar to Anderson and Pildes' Christian symbols example - those who do not share particular views, in this case the view that the benefits of breastfeeding should take priority over other goals that individuals might want to pursue. ${ }^{30}$

\subsection{Failing to give equal weight to some individuals' interests}

Scheffler has recently suggested that an important aspect of the kind of egalitarian relationships that relational egalitarians pursue is that

each member [of a society] accepts that every other member's equally important interests should play an equally significant role in influencing decisions made on behalf of the society as a whole... a society of equals is characterised by a reciprocal commitment on the part of each member to treat the equally important interests of every other member as exerting equal influence on social decisions. (Scheffler 2015, pp. 35-36)

While Scheffler's concern seems primarily to be about people's actual attitudes towards their co-citizens, we could also think that the expressive content of state action would be subject to similar requirements: that it should express a willingness to give equal weight to equally important interests or, more broadly, to give appropriate weight to all citizens' relevant interests.

The expressive content of breastfeeding campaigns could also be interpreted along these lines. As I mentioned, many of these campaigns recommend exclusive breastfeeding for six months as the standard that mothers should deviate from only under exceptional circumstances. This might be plausible if deviating from this standard exposed children to substantial and certain risks. However, as I

30 For a related discussion of breastfeeding recommendations, see Balint et al. (2017). While their discussion has a different focus than mine, many of their concerns about breastfeeding recommendations - the problematic evidence base, how evidence is presented, gender equality, etc. - are also important to the argument developed here. 
discussed above, this does not appear to be the case (or, at least, such recommendations have been issued on the basis of evidence that is not sufficient to permit this conclusion).

The recommendations typically make little attempt to give weight to women's interests in not breastfeeding and the idea that because of these costs, they might quite reasonably decide that they will not breastfeed. One way to read the move from the evidence about the benefits of breastfeeding (given the uncertainties around it) straight to the conclusion that women ought to breastfeed is that in coming to this conclusion, women's interests matter very little. Giving appropriate weight to mothers' interests would require an acknowledgement of possible costs associated with breastfeeding (which may also vary from person to person) and that these costs must be weighed against the possible benefits of breastfeeding. Simply concluding that mothers should breastfeed, based on the evidence presented, can therefore be taken to convey a failure to give appropriate weight to the interests of relevant parties - in this case, mothers. ${ }^{31}$

Again, what matters from an expressive dimension is the attitude expressed - in this case, the seeming lack of a disposition to give appropriate weight to the interests of mothers when it comes to breastfeeding decisions. This concern is again independent of the actual effects these policies might have, e.g. if mothers were to engage in an appropriate assessment of all considerations, giving appropriate weight to all parties' relevant interests, including their own.

\subsection{Expressing disrespect for individuals' decision-making capacities}

A different expressive meaning that state action might convey is disrespect for people's authority over certain spheres of their lives. ${ }^{32}$ This concern is articulated particularly clearly in relation to paternalistic interventions. Some of the literature objects to paternalism, not primarily because of the liberty restrictions it implies, but because of the attitudes such interventions express towards the person who is interfered with. These arguments share central concerns of relational egalitarianism and also seem

31 The more recent DHHS breastfeeding report seems somewhat more sensitive to these issues. This report often frames its recommendations in terms of mothers wanting to breastfeed and the importance of removing obstacles to mothers being able to act in accordance with this preference, rather than the recommendation being independent of what mothers in fact want (Department of Health and Human Services 2011). This move, of course, may come with its own problems in that it assumes that wanting to breastfeed is 'normal' for mothers.

32 This section draws on Voigt (2015). 
to pick up expressive concerns. ${ }^{33}$ Seana Shiffrin (2000) has argued that paternalistic interventions stipulate an asymmetry of knowledge and competency between the agents involved. From this perspective, the expression of disrespect is a central feature of paternalistic interventions:

The essential motive behind a paternalistic act evinces a failure to respect either the capacity of the agent to judge, the capacity of the agent to act, or the propriety of the agent's exerting control over a sphere that is legitimately her domain ... Paternalistic behaviour is special because it represents a positive ... effort by another to insert her will and have it exert control merely because of its (perhaps only alleged) superiority. As such, it directly expresses insufficient respect for the underlying valuable capacities, powers, and entitlements of the autonomous agent. Those who value equality and autonomy have special reason to resist paternalism toward competent adults. (Shiffrin 2000, p. 220)

Douglas Husak, too, explicitly describes this concern in terms of the inequality expressed by an endorsement of paternalistic interference: 'If a paternalistic relationship involves superiority and inferiority, the sense of equality that underlies such formulations of the autonomy principle is repudiated. On this view, there would be no place for paternalism in a world in which each agent regarded all others as moral equals' (Husak 1981, p. 41).

As I mentioned earlier, the requirements of relational equality are sometimes described in ways that focus on people's attitudes towards one another and the willingness to treat others as equals (e.g. Scheffler 2015). Concerns about paternalism might then be described as straightforwardly violating the requirements of relational equality (treating someone with disrespect), without referring to the expressive dimension. For example, Husak's concern that if we regarded each other as equals, there would be no place for paternalism could be described in fairly straightforward relational terms. Is there still scope for a distinctly expressive concern here, in addition to the kinds of concerns that relational egalitarians can describe without recourse to expressive considerations? Arguably, state action that permits (or fails to protect individuals from) paternalistic interference could be taken to express particular attitudes about (some) citizens' decision-making capacities; consider, for example, legislation with respect to involuntary hospitalisation of those with mental health conditions. This would be distinct from concern about individuals' attitudes towards one another in interpersonal interactions. Thus, as with state legislation permitting employers to exclude smokers from employment, the state, by permitting paternalistic interference, could be expressing problematic attitudes, irrespective of whether this actually leads to such interference.

33 To my knowledge, relational egalitarians themselves have not addressed this issue explicitly. Anderson (1999) mentions paternalistic interventions as straightforwardly problematic but does not explain the reasoning underlying this judgment. 


\subsection{Failing to acknowledge background injustices affecting individuals' choices}

Anderson and Pildes suggest that states, after inflicting harm on citizens, may engage in actions that express 'appropriate condemnation' of this harm so as to re-establish relationships of equality (Anderson and Pildes, 2000, p. 1529). While they focus on situations in which states express condemnation for harm they have inflicted on citizens, states can also express condemnation of harm or injustice for which they were not responsible. Along these lines, we might also think that the expressive content of state action is problematic when legislators fail to recognise the effects of background injustices and inequalities on citizens. Background inequalities affect both the impact of state action on individuals and how that state action is understood. At a non-ideal level, treating people as equals and with equal concern and respect might then also require a recognition of the inequalities and injustices they are subject to, for example by explicitly acknowledging these injustices or by rejecting legislation that would further burden those who are already disadvantaged (even if such legislation would, in more egalitarian circumstances, be unproblematic).

For example, in a legal context where same-sex couples are prevented from getting married, a government might reject legislation that would extend tax benefits to married couples, on the grounds that this further advantages heterosexual couples vis-à-vis same-sex couples. The expressive content of such a refusal might be something like, 'we recognise that same-sex couples are already disadvantaged by existing, unjust social norms and legislation, and for that reason will not permit legislation that further advantages heterosexual couples'. Conversely, a government's willingness to introduce tax benefits for married couples in such a context could express their indifference to the injustices suffered by some of its citizens.

In a context where background inequalities affect people's ability to engage in certain behaviours and/or to avoid certain risks, ${ }^{34}$ insisting that people make particular choices fails to recognise the inequalities that affect individuals' ability to comply with the recommendations issued. Again, the breastfeeding campaigns discussed above may also be susceptible to this concern: breastfeeding may be difficult or burdensome for a number of reasons, and women's ability to comply with the recommended breastfeeding arrangements will vary in light of the level of material (dis)advantage they face, the degree to which their employers are willing to accommodate their breastfeeding, etc. Making prescriptive statements about breastfeeding that do not acknowledge these inequalities could become

34 A possible problem for relational egalitarians (though not for the pluralist egalitarian view I've been assuming): to the extent that the concern here is with distributive inequalities that relational egalitarians may not consider problematic and of themselves, a purely relational view may not fully capture what I have in mind in this section. 
problematic by failing to express recognition of how background inequalities shape and constrain breastfeeding choices.

\section{Conclusion}

Expressive accounts highlight the importance of attitudes and meanings implicit in state action and can capture important considerations of relational equality. The idea that state action should be evaluated not just with respect to its direct effects but also with respect to what it expresses is, I think, compelling. In this paper, I argued that the account relational egalitarians have provided of how we should think of the expressive dimension of state action needs to be revised in several respects. I suggested that expressive considerations should be tied more closely to the actual attitudes of the authors of the action as well as to their intentions. With the revised account in place, I highlighted several ways in which different policies can have expressive content that violates requirements of relational equality. Taking the expressive dimension of state action into account allows for a more nuanced assessment of state policy and a clearer understanding of what relational equality requires of states and their institutions. ${ }^{35}$

\section{Works cited}

Adler, M. D. (2000a). Expressive Theories of Law: A Skeptical Overview. University of Pennsylvania Law Review, 148(5), 1363-1501.

Adler, M. D. (2000b). Linguistic Meaning, Nonlinguistic "Expression," and the Multiple Variants of Expressivism: A Reply to Professors Anderson and Pildes. University of Pennsylvania Law Review, 148(5), 1577-1594.

Altman, A. (1993). Liberalism and Campus Hate Speech: A Philosophical Examination. Ethics, 103(2), 302-317.

Altman, A. (1999). Expressive meaning, race, and the law. Legal Theory, 5, 75-99.

Altman, A. (2002). Speech Codes and Expressive Harms. In Ethics in Practice (2nd ed., pp. 376-385). Oxford: Oxford University Press.

Anderson, E. (1999). What is the Point of Equality? Ethics, 109(2), 287-337.

Anderson, E. (2008). How Should Egalitarians Cope with Market Risks? Theoretical Inquiries in Law, 9(1), 239-270.

Anderson, E. (2009). Toward a Non-Ideal, Relational Methodology for Political Philosophy: Comments on Schwartzman's Challenging Liberalism. Hypatia, 24(4), 130-145.

35 Acknowledgments: This paper has benefitted greatly from the comments and suggestions I received from audiences at the Centre de recherche en éthique (Montreal), the University of Seattle, the University of Münster, Oxford University, the University of Edinburgh, the Dublin Political Theory workshop, and the Annual Meeting of the Society for Applied Philosophy, where earlier versions were presented. For detailed comments, I'd like to thank John Baker, Éliot Litalien, Natalie Stoljar, Kasper Lippert-Rasmussen, David O’Brien and Adina Preda. I am grateful for support from the Fonds de recherche du Québec - Société et culture (FRQ-SC) (grant no. 172569) and the Social Sciences and Humanities Research Council (SSHRC) (grant no. 430-2016-01205). 
Anderson, E. (2010). The Imperative of Integration. Princeton: Princeton University Press.

Anderson, E., \& Pildes, R. (2000). Expressive Theories of Law: A General Restatement. University of Pennsylvania Law Review, 148(5), 1503-1575.

Asch, D. A., Muller, R. W., \& Volpp, K. G. (2013). Conflicts and Compromises in Not Hiring Smokers. New England Journal of Medicine, 368(15), 1371-1373.

Baker, J. (2015). Conceptions and dimensions of social equality. In C. Fourie, F. Schuppert, \& I. Wallimann-Helmer (Eds.), Social Equality: On what it means to be equals (pp. 65-86). Oxford University Press.

Balint, P., Eriksson, L., \& Torresi, T. (2017). State power and breastfeeding promotion: A critique. Contemporary Political Theory, 142(5), 1-25.

Bishop, G., \& Brodkey, A. C. (2006). Personal responsibility and physician responsibility--West Virginia's Medicaid plan. New England Journal of Medicine, 355(8), 756-758.

Cloarec, P. (2017). Social Equality and the Global Society. Journal of Moral Philosophy, 14(5), 535-561.

Cohen, G. A. (2014). Notes on regarding people as equals. In M. Otsuka (Ed.), Finding Oneself in the Other (pp. 193-200). Princeton: Princeton University Press.

Daniels, N. (2011). Individual and social responsibility for health. In C. Knight \& Z. Stemplowska (Eds.), Responsibility and Distributive Justice (pp. 266-285). Oxford: Oxford University Press.

Department of Health and Human Services. (2000). HHS Blueprint for Action on Breastfeeding. Washington, D.C.: U.S. Department of Health and Human Services. http://www.pnmc-hsr.org/wp-content/uploads/2011/01/BreastfeedingBlueprint.pdf

Department of Health and Human Services. (2011). The Surgeon General's Call to Action to Support Breastfeeding. https://www.surgeongeneral.gov/library/calls/breastfeeding/calltoactiontosupportbreastfeeding.pdf

Dworkin, R. (1977). Taking rights seriously. Cambridge, Mass.: Harvard University Press.

Fenton, E. (2013). Mind the Gap: ethical issues of private treatment in the public health system. New Zealand Medical Journal, 124(1334), 89-96.

Fourie, C. (2011). What is Social Equality? An Analysis of Status Equality as a Strongly Egalitarian Ideal. Res Publica, 18(2), 107-126.

Fourie, C. (2016). Sufficiency of capabilities, social equality and two-tiered health care systems. In C. Fourie \& A. Rid (Eds.), What Is Enough? Sufficiency, Health and Justice (pp. 185-204). New York: Oxford University Press.

Gheaus, A. (2016). Hikers in Flip-Flops: Luck Egalitarianism, Democratic Equality and the Distribuenda of Justice. Journal of Applied Philosophy, 35(1), 54-69.

Hellman, D. (2000). The Expressive Dimension of Equal Protection. Minnesota Law Review, 85, 1-71.

Husak, D. N. (1981). Paternalism and autonomy. Philosophy and Public Affairs, 10(1), 27-46.

Kelleher, J. P. (2016). Health Inequalities and relational egalitarianism. In R. Walker, M. Buchbinder, \& M. Rivkin-Fish (Eds.), Understanding Health Inequalities and Justice: Bridging Perspectives for New Conversations (pp. 88-111). Chapel Hill: University of North Carolina Press.

Kukla, R. (2006). Ethics and ideology in breastfeeding advocacy campaigns. Hypatia, 21(1), 157-180.

Landes, X., \& Néron, P. Y. (2015). Public Insurance and Equality: From Redistribution to Relation. Res Publica, 21(2), 137-154.

Lippert-Rasmussen, K. (2014). Born Free and Equal? A Philosophical Inquiry Into the Nature of Discrimination. New York: Oxford University Press.

Lippert-Rasmussen, K. (2015). Luck Egalitarianism. London: Bloomsbury Academic.

Miller, D. (1997). Equality and justice. Ratio, 10(3), 222-237.

Nath, R. (2014). Equal standing in the global community. The Monist, 94(4), 593-614. 
Nath, R. (2015). On the scope and grounds of social equality. In C. Fourie, F. Schuppert, \& I. Wallimann-Helmer (Eds.), Social Equality: On what it means to be equals (pp. 186-208). Oxford: Oxford University Press.

Parekh, B. (2006). Hate speech: is there a case for banning? Public Policy Research, 12(4), 213-223.

Pildes, R. H., \& Anderson, E. S. (1990). Slinging Arrows at Democracy: Social Choice Theory, Value Pluralism, and Democratic Politics. Columbia Law Review, 90(8), 2121-2214.

Pildes, R. H., \& Niemi, R. G. (1993). Expressive Harms, "Bizarre Districts," and Voting Rights: Evaluating Election-District Appearances After Shaw v. Reno. Michigan Law Review, 92(3), 483-587.

Pogge, T. (2004). Relational conceptions of justice: responsibilities for health outcomes. In S. Anand, F. Peter, \& A. Sen (Eds.), Public Health, Ethics, and Equity (pp. 135-161). Oxford: Oxford University Press.

Rawls, J. (1996). Political Liberalism. New York: Columbia University Press.

Scheffler, S. (2003). What is Egalitarianism? Philosophy and Public Affairs, 31(1), 5-39.

Scheffler, S. (2015). The practice of equality. In C. Fourie, F. Schuppert, \& I. Wallimann-Helmer (Eds.), Social Equality: On what it means to be equals (pp. 21-44). Oxford: Oxford University Press.

Schemmel, C. (2012). Distributive and relational equality. Politics, Philosophy and Economics, 11(2), 123148.

Schmidt, H., Voigt, K., \& Emanuel, E. (2013). The Ethics of Not Hiring Smokers. New England Journal of Medicine, 368(15), 1369-1371.

Shiffrin, S. (2000). Paternalism, unconscionability doctrine, and accommodation. Philosophy and Public Affairs, 29(3), 205-250.

Sunstein, C. (1995). On the expressive function of law. University of Pennsylvania Law Review, 144(5), 2021-2053.

Voigt, K. (2012a). Incentives, health promotion and equality. Health Economics, Policy and Law, 7(3), $263-283$.

Voigt, K. (2012b). Nonsmoker and "Nonnicotine" Hiring Policies: The Implications of Employment Restrictions for Tobacco Control, American Journal of Public Health 102(11), 2013-2018.

Voigt, K. (2015). Paternalism and Equality. In T. Schramme (Ed.), New Perspectives on Paternalism and Health Care (pp. 87-100). Amsterdam: Springer.

Voigt, K. (2017). Distributive equality, relational equality, and preferences about higher education. Theory and Research in Education, 15(2), 109-128.

Voigt, K., \& Wester, G. (2015). Relational equality and health. Social Philosophy and Policy, 31(2), 204229.

Tomlin, P. (2014). What is the point of egalitarian social relationships? In A. Kaufman (Ed.), Distributive Justice and Access to Advantage (pp. 151-179). Cambridge: Cambridge University Press.

Weinstock, D. M. (2011). How should political philosophers think of health? The Journal of Medicine and Philosophy, 36(4), 424-435.

Wolff, J. (2000). Levelling down. In K. Dowding, J. Hughes, \& H. Margetts (Eds.), Challenges to Democracy Ideas, Involvement and Institutions (pp. 18-32). Basingstoke: Palgrave. 